\title{
Total mercury and selenium concentrations in Sarpa salpa and Balistes capriscus and in their respective Digenean endoparasites Robphildollfusium fractum and Neoapocreadium chabaudi from Tunisia
}

\author{
Jordi Torres ${ }^{1,2}$, Hichem Kacem ${ }^{3}$, Catarina Eira ${ }^{4,5}$, Lassad Neifar ${ }^{3}$ and Jordi Miquel ${ }^{1,2}$ \\ ${ }^{1}$ Departament de Microbiologia i Parasitologia Sanitàries, Facultat de Farmàcia, Universitat de Barcelona, Av. Joan XXIII, sn, \\ 08028 Barcelona, Spain; ${ }^{2}$ Institut de Recerca de la Biodiversitat, Universitat de Barcelona, Av. Diagonal, 645, 08028 Barcelona, Spain; \\ ${ }^{3}$ Laboratoire de Biodiversité et Ecosystèmes Aquatiques, Département des Sciences de la Vie, Faculté des Sciences de Sfax, 3000 Sfax, \\ Tunisia; ${ }^{4}$ CESAM \& Departamento de Biologia, Universidade de Aveiro, Campus de Santiago 3810-193 Aveiro, Portugal; \\ ${ }^{5}$ Sociedade Portuguesa de Vida Selvagem, Estaçao de Campo de Quiaios, Apartado 16 EC Quiaios 3081-101 Figueira da Foz, Portugal
}

\begin{abstract}
The present study reports the levels of mercury and selenium in Sarpa salpa and Balistes capriscus collected along the coast of Mahdia and Sfax (Tunisia). The systems constituted by S. salpa and Robphildollfusium fractum and by B. capriscus and Neoapocreadium chabaudi were tested as potential bioindicators to monitor environmental $\mathrm{Hg}$ pollution in marine ecosystems. Mercury and selenium concentrations were assessed in kidney, liver and muscle of $51 \mathrm{~S}$. salpa and of 45 B. capriscus as well as in their respective endoparasites $R$. fractum and $N$. chabaudi. The Se:Hg molar ratios were evaluated for both species across the study areas. Surprisingly, the Se:Hg molar ratio in B. capriscus muscle from Mahdia is significantly lower than in Sfax. Our results indicate that some parasites may also be implicated in the amount of Se and $\mathrm{Hg}$ available in tissues and therefore contribute to oscillations of the Se:Hg molar ratios. In the model involving the carnivorous species (B. capriscus), the 5.1-times higher levels of mercury in $N$. chabaudi than in B. capriscus muscle in Sfax enable this fluke to be a sensitive biomonitoring tool for $\mathrm{Hg}$ pollution. The present results confirm that the habitual consumption of $S$. salpa should not suppose any potential health risk for Tunisian people. On the other hand, the consumption of $B$. capriscus may be of concern and further monitoring is advisable, since the $\mathrm{Hg}$ average concentration in Mahdia was above the maximum allowed $\mathrm{Hg}$ concentration in the edible portion of fish fixed by the European Union.
\end{abstract}

\section{Keywords}

Mercury, Selenium, Se:Hg molar ratio, Sarpa salpa, Balistes capriscus, Robphildollfusium fractum, Neoapocreadium chabaudi, Tunisia

\section{Introduction}

Several pollutants are continuously being introduced into marine ecosystems as a consequence of several sources. Heavy metals are persistent pollutants that can be accumulated by marine organisms through a variety of pathways and they are biomagnified in the food chains, becoming increasingly dangerous for human consumption. In this respect, special attention should be taken to the exogenous harmful mercury and also to selenium, an essential element acting as a protective agent against the toxicity of mercury (WHO 1987; USA/EPA 1998; Burger and Gochfeld 2011).

Adequate assess of ecosystem health by means of biomonitoring requires selecting representative species that allow compiling data in a wide range of their distribution in order to obtain more valuable and representative results. Among others, several teleostei fish species, which constitute an important part of the human diet, have been widely used to monitor marine mercury pollution (Usero et al. 2003; Türkmen et al. 2008; Aksu et al. 2011; Mezghani-Chaari et al. 2011). 
In Tunisia, fishing is an important income source throughout the country, where different levels of pollution occur according to each region's main economic activity (eg, industry, tourism). Therefore, monitoring $\mathrm{Hg}$ pollution in common edible fish species is necessary.

The use of helminth parasites as bioindicators for heavy metal environmental pollution in aquatic ecosystems is commonly accepted since some species can accumulate high amounts of toxic elements even with a greater extent than free living organisms commonly used for monitoring water pollution (Sures 2003, 2008). Acanthocephalans are presently recognized for their excellent metal accumulation capacities in both field and experimental conditions and adult cestodes as well as nematodes also seem to be promising bioindicators for some toxic elements (Eira et al. 2009; Dural et al. 2011). However, there is no data concerning adult trematodes parasites of fish.

The main objective of this study was to determine the levels of mercury and selenium in the edible part as well as in other tissues of the cow bream Sarpa salpa (Linnaeus, 1758) (Teleostei: Sparidae) and the grey triggerfish, Balistes capriscus Gmelin, 1789 (Teleostei: Balistidae) collected in the coast of two different Tunisian governorates (Sfax and Mahdia) with different degrees of industrialization. The present work also evaluates for the first time two fish systems involving adult trematodes S. salpa/Robphildollfusium fractum Paggi and Orecchia, 1963 (Lepocreadioidea: Gyliauchenidae) and $B$. capriscus/Neoapocreadium chabaudi Kohn and Fernandes, 1982 (Lepocreadioidea: Apocreadiidae) in order to determine the potential usefulness of these systems as bioindicators of mercury in the marine environment.

\section{Materials and Methods}

Tunisia has a 1,298 Km long Mediterranean coastline, where the governorates of Sfax and Mahdia are located. The coastal area off the city of Sfax, well-known for fisheries and industrial activities, receives several man made discharges enriched with organic matter nutriments and heavy metals (Serbaji et al. 2012). Contrarily, the touristic city of Mahdia seems to be only influenced by a minimal industrial pollution or anthropogenic effluents.

To perform the present study 51 specimens of $S$. salpa parasitized by $R$. fractum collected in 2009 using fishing nets along the coasts of Sfax (24 specimens) and Mahdia (27 specimens) and 45 specimens of $B$. capriscus parasitized by $N$. chabaudi collected during the same period using specific gill nets and hand lines (24 specimens from Sfax and 21 from Mahdia) were selected. After capture all fish specimens were immediately analysed removing their digestive tracts and scanning them for helminths by means of standard helminthological methods. Stainless steel instruments and Milli-Q water were always used. After species identification all individuals of $R$. fractum and N. chabaudi respectively collected from the intestine of $S$. salpa and B. capriscus individuals used in the present work were frozen in glass vials $\left(-20^{\circ} \mathrm{C}\right)$ until posterior element analysis. In addition, samples of kidney, liver and muscle of all infected fishes were collected during dissection. These samples were stored in glass vials and frozen $\left(-20^{\circ} \mathrm{C}\right)$ until posterior processing as described below.

All the analytical process was performed in the "Centres Científics i Tecnològics de la Universitat de Barcelona (CCiTUB)" (certified according to ISO 9001:2008). Tissue samples were weighed $( \pm 150 \mathrm{mg}$ wet weight) as well as $R$. fractum and $N$. chabaudi specimens and then digested in Teflon vessels with $\mathrm{HNO}_{3}(2 \mathrm{ml})$ and $\mathrm{H}_{2} \mathrm{O}_{2}(1 \mathrm{ml})$ (Merck, Suprapure). Samples were left overnight at $90^{\circ} \mathrm{C}$ in an oven. All materials used in the process were thoroughly acid-rinsed. After digestion, samples were diluted with Milli-Q water and then they were analysed for Hg and Se by ICP-MS (Perkin Elmer Elan 6000). The analytical procedure was checked using samples of standard reference material Dogfish (Squalus acanthias) liver (DOLT-3) and muscle (DORM-2) from the National Research Council, Canada. Results for total mercury DOLT-3 were 0.37 $\pm 0.14 \mathrm{mg} \mathrm{Kg}^{-1}$ and the certified value was $0.382 \pm 0.06 \mathrm{mg}$ $\mathrm{Kg}^{-1}$ (96.8\% accuracy). Results for selenium DORM-2 were $1.35 \pm 0.17 \mathrm{mg} \mathrm{Kg}^{-1}$ and the certified value was $1.40 \pm 0.09$ $\mathrm{mg} \mathrm{Kg}^{-1}$ (96.4\% accuracy). Analytical blanks were also prepared and analysed along with samples in order to determine the detection limits, which were $0.11 \mathrm{ng} \mathrm{ml}^{-1}$ for mercury and $0.28 \mathrm{ng} \mathrm{ml}^{-1}$ for selenium.

The data obtained did not follow a normal distribution even after $\log (\mathrm{x}+1)$ transformation. Therefore, the differences between element concentrations among the analysed tissues in both species and both sampling sites were assessed by the Kruskal-Wallis test and post-hoc Dunn's test. The Mann Whitney test was also used to compare concentration values in parasites across study areas and also to compare $\mathrm{Se}: \mathrm{Hg}$ molar ratios among fish species and study areas. Linear regression was used to assess relationships between element concentrations in different tissues and parasites. Statistical analyses were performed in Prism 5 and JMP 9. For all tests, a significance level of $\mathrm{p}<0.05$ was applied. All concentrations are expressed in parts per billion ( $\mathrm{ppb}=\mathrm{ng} / \mathrm{g}$ ) on a wet weight basis. The molar concentrations were obtained by dividing by the molecular weight (200.59 for $\mathrm{Hg}$ and 78.9 for $\mathrm{Se}$ ) as proposed by Burger and Gochfeld (2011). The bioaccumulation factors were determined according to Sures et al. (1999), as the ratio of the element concentration in the parasites to that in different host tissues $\left(\mathrm{BF}=\mathrm{C}_{\text {[parasite] }} / \mathrm{C}_{\text {[host tissue }]}\right)$.

\section{Results}

Mercury and selenium concentrations found in kidney, liver, and muscle of $S$. salpa and B. capriscus from both localities as well as in their respective flukes $R$. fractum and $N$. chabaudi are shown in Table I. The Se:Hg molar ratios in the fish edible portion are also presented in Table I. 
Many significant differences were found among the concentration values obtained for each tissue in each fish species and across prospected study areas. In this study we will focus on the edible portion of the analysed fish species. With respect to fish muscle, no significant differences were found between the concentrations of $\mathrm{Hg}$ in $\mathrm{S}$. salpa neither between the concentrations of $\mathrm{Hg}$ in B. capriscus from both study areas. However, in both study areas $S$. salpa muscle Hg concentrations were lower than those found for B. capriscus (Kruskal-Wallis, $\mathrm{H}=75.56, \mathrm{p}<0.0001$, Dunn's test, all $\mathrm{p}<0.0001$ except between $S$. salpa and B. capriscus from Sfax, $\mathrm{p}<0.01$ ). Similarly, significant differences were not found between Se muscle concentrations neither in S. salpa nor in B. capriscus from both study areas. However, the Se muscle concentrations in $S$. salpa were lower than those in $B$. capriscus in both study areas $(\mathrm{H}=72.98, \mathrm{p}<0.0001$, Dunn's test, all $\mathrm{p}<0.0001)$.

With respect to the parasite $R$. fractum infecting $S$. salpa, the $\mathrm{Hg}$ concentration was always below the detection limit. The Se concentration in $R$. fractum from Mahdia was higher than that in $R$. fractum from Sfax (Mann-Whitney, $\mathrm{U}=92$, $\mathrm{p}<0.0001)$. On the other hand, there was a higher concentration of Se in N. chabaudi infecting B. capriscus from Mahdia in relation to those from $\mathrm{Sfax}(\mathrm{U}=155, \mathrm{p}=0.0281)$. The $\mathrm{Hg}$ concentration in $N$. chabaudi infecting B. capriscus from Mahdia was lower than that in $N$. chabaudi infecting B. capriscus from $\mathrm{Sfax}(\mathrm{U}=128, \mathrm{p}=0.005)$. There was a significant negative relationship between the Se concentrations in the parasite $R$. fractum and host muscle in Mahdia $\left(\mathrm{F}_{1,26}=6.1856, \mathrm{p}=0.0199\right)$.

The Se:Hg molar ratio in S. salpa muscle from Mahdia was significantly higher than in $S$. salpa muscle from Sfax whereas the $\mathrm{Se}: \mathrm{Hg}$ molar ratio in B. capriscus muscle from Mahdia was significantly lower than in $\operatorname{Sfax}(U=159, p=$ 0.0019 and $U=20, p<0.0001)$. In Mahdia, the Se:Hg molar ratio in $S$. salpa muscle was significantly higher than in B. capriscus muscle whereas in Sfax, there were no significant differences between the Se:Hg molar ratio in S. salpa and B. capriscus muscle tissues $(\mathrm{U}=1, \mathrm{p}<0.0001$ and $\mathrm{U}=252$, $\mathrm{p}<0.4642$ ).

The bioaccumulation factors of both flukes are indicated in Table II. The highest bioaccumulation factor was found for $\mathrm{Se}$, with a 7.1-times higher average concentration in $R$. fractum in comparison to muscle of $S$. salpa from Mahdia. With respect to $\mathrm{Hg}$, the highest bioaccumulation factor was 5.1times higher in $N$. chabaudi in comparison to muscle of B. capriscus from Sfax.

\section{Discussion}

Accumulation of pollutants in fish is of increasing concern due to food safety issues and potential human health risks, such as those related with hydrargyriasis, a disease caused by the intake of high doses of mercury producing toxic effects, which include brain, kidney and lung damage leading to a 
number of other pathologies. Mercury occurs naturally in seawater, and coastal waters receive mercury runoff from land, input from rivers, and airborne deposition. Biomethylation of mercury (leading to the most toxic form of mercury) occurs in sediment, allowing for food chain biomagnification (WHO 2007). According to Scudder et al. (2009), about $95 \%$ of mercury in fish is methylmercury. Nowadays, fish ingestion is the only significant source of methylmercury for people in general (Rice et al. 2000) and therefore the mercury concentration in foodstuffs is strictly regulated by several international organisms and laws. For example, in the European Union the maximum limit of $\mathrm{Hg}$ in edible fish is 0.5 or $1.0 \mathrm{ppm}$ (wet weight) according to fish species (Official Journal of the European Union 2006).

Unlike some edible top food web fish species (e.g. Thunnus spp., Xiphias gladius), studies focusing on mercury concentrations in teleostei fish, including Sparidae and Balistidae, are much scarcer (Türkmen et al. 2008; Mezghani-Chaari et al. 2011). As expected, the values obtained in the present study revealed that the omnivorous species (B. capriscus) accumulates much more mercury than the herbivorous species (S. salpa). Mezghani-Chaari et al. (2011) also analysed the mercury concentration in the edible parts of two Sparidae fish (Diplodus annularis and S. salpa) from Sidi Mansour (12 Km to the north of Sfax) and reported mean concentrations of 1100 and $80 \mathrm{ppb}$ wet weight, respectively. The value obtained in $S$. salpa by the latter authors is very similar to that observed in the present study (74.9 ppb) in the muscle of cow breams from Sfax whereas the level of mercury reported in D. annularis was higher than the herein reported in B. capriscus from Sfax (212 ppb). In both studies the concentration of mercury in the herbivorous $S$. salpa, feeding at the lower levels of the food chain, is much lower than those in the omnivorous D. annularis and B. capriscus.

The present results confirm that mercury levels found in S. salpa from Mahdia and Sfax were well below the tolerable concentration $(0.5 \mu \mathrm{g} / \mathrm{g}$ wet weight) fixed by the Official Journal of the European Union (2006). Therefore, the habitual consumption of $S$. salpa should not suppose any potential health risk for Tunisian people. However, the consumption of B. capriscus in Mahdia appears to represent a potential health risk for Tunisian people since the $\mathrm{Hg}$ average concentration $(0.53 \mathrm{ppm})$ in $B$. capriscus muscle was slightly above the maximum limit of $\mathrm{Hg}$ allowed in edible fish $(0.50 \mathrm{ppm})$ according to the Official Journal of the European Union (2006). The lack of statistical significance between muscular mercury concentrations in B. capriscus from both areas may reduce the concern associated with the potential health risk to B. capriscus consumers from Mahdia.

Part of the toxicity associated with mercury is related to the negative effect that inorganic mercury and methylmercury can exert on selenium-dependent enzymes (Carvalho et al. 2008; Pinheiro et al. 2009; Ralston 2009). On the other hand, selenium is though to have a protective effect against mercury toxicity (Kaneko and Ralston 2007; Ralston 2008, 2009; Ralston et al. 2008; Burger and Gochfeld 2012) mainly because of the high affinity of selenium to mercury. In fact, selenium is thought to sequester methylmercury and reduce its bioavailability in organisms (Sørmo et al. 2011). Several authors have argued that higher Se:Hg molar ratios indicate a more protective effect of selenium against mercury toxicity (Ralston 2008; Peterson et al. 2009a, b), even though contradictory results indicate that the effect of selenium on mercury bioaccumulation is an extremely complex process (Dang and Wang 2011). There has been a growing concern about the evaluation of $\mathrm{Se}: \mathrm{Hg}$ molar ratios in fish muscle with focus on the methylmercury toxicity for humans as consumers of fish (Kaneko and Ralston 2007; Ralston 2008, 2009; Ralston et al. 2008; Burger and Gochfeld 2012). In the present study, the muscular Se:Hg molar ratio in S. salpa from Mahdia was significantly higher than in S. salpa from Sfax. Considering that there were no differences between Se concentrations in $S$. salpa muscle from both areas nor between Se concentrations in B. capriscus muscle from both areas, the differences detected between the $\mathrm{Se}: \mathrm{Hg}$ molar ratio in S. sarpa muscle across study areas should result from the slightly higher concentration of $\mathrm{Hg}$ in $\mathrm{S}$. salpa muscle from Sfax. Also, no significant differences were found between $\mathrm{Se}$ or between $\mathrm{Hg}$ muscle concentrations in B. capriscus from both areas. However, the Se:Hg molar ratio in B. capriscus muscle from Mahdia is significantly lower than in Sfax (higher $\mathrm{Hg}$ and lower $\mathrm{Se}$ in Mahdia than in Sfax). Furthermore, a higher concentration of selenium was found in $N$. chabaudi infecting $B$. capriscus from Mahdia in relation to those from Sfax. These results indicate that Se is being accumulated in $N$. chabaudi infecting B. capriscus from Mahdia while in Sfax Se is being used in fish tissue possibly for its protective effect against mercury toxicity.

Higher metal concentrations in fish parasites than in host fish tissues are based on the parasite reliance on host mi-

Table II. Bioaccumulation factors in Robphildollfusium fractum and Neoapocreadium chabaudi in relation to Sarpa salpa and Balistes capriscus tissues, respectively

\begin{tabular}{|c|c|c|c|c|c|c|c|}
\hline & & \multicolumn{2}{|c|}{$\mathbf{B F}_{\text {kidney }}$} & \multicolumn{2}{|c|}{$\mathbf{B F}_{\text {liver }}$} & \multicolumn{2}{|c|}{$\mathbf{B F}_{\text {muscle }}$} \\
\hline & & Mahdia & Sfax & Mahdia & Sfax & Mahdia & Sfax \\
\hline N. chabaudi & $\mathrm{Hg}$ & & & & & 1.6 & 5.1 \\
\hline R. fractum & $\mathrm{Se}$ & 1.7 & & 1.1 & & 7.1 & 2.5 \\
\hline N. chabaudi & $\mathrm{Se}$ & & & 1.6 & 1.8 & 4.7 & 4.2 \\
\hline
\end{tabular}


cronutrients, mainly if they lack a gastrointestinal system. For example, acanthocephalans absorb essential elements of physiological importance from the intestine of their fish hosts (Sures 2002) and, therefore, the increased absorption of nonessential elements might be a consequence of competition between parasites and their hosts for essential elements. Furthermore, the absorption of both essential and toxic elements through the tegument can be influenced by the element itself, the size of the worm, the infected microhabitat, and the concrete location in the intestine and some particularities in the absorption process. Until now there is no information about the bioaccumulation of mercury and selenium by fluke parasites of marine fish. In $R$. fractum only selenium could be quantified probably due to the very low level of mercury in the intestine of its herbivorous fish host ( $S$. salpa). The mean selenium bioaccumulation factors detected in $R$. fractum were 2.5 and 7.1-times higher than those found in cow bream muscle from Sfax and Mahdia, respectively. Furthermore, our results showed that in the case of Mahdia, increasing concentrations of selenium in $R$. fractum individuals are significantly related with its decreasing concentration in host muscle. However, no significant differences were found between Se concentrations in $S$. salpa muscle from both study areas, neither between $B$. capriscus muscle from both study areas, which is consistent with some degree of homeostatic regulation. Also, it seems that in fact when mercury pollution is higher flukes take up less selenium from their host, being probably used in mercury detoxification processes. Contrarily, in fishes with less mercury in their tissues selenium are most available to digenids increasing the bioaccumulation factors. In the model involving the carnivorous species (B. capriscus), larger and more mobile than $S$. salpa, it was possible to quantify the mercury concentration in $N$. chabaudi specimens but with a mean concentration lower than those in all analysed tissues and study areas except in both muscle samples (Table II). Therefore, the 5.1-times higher levels of mercury in $N$. chabaudi than in B. capriscus muscle in Sfax enable this fluke to be a sensitive bioindicator.

The present results indicate that some parasites may also be implicated in the amount of selenium and mercury available in different tissues of their hosts and therefore contribute to oscillations of the $\mathrm{Se}: \mathrm{Hg}$ molar ratios. It is possible that the evaluation of several molar ratios should be more appropriate to test different effects, tissues and species (Burger and Gochfeld 2013). Further studies on selenium levels and mercury toxicity are necessary (Peterson et al. 2009a) to clarify the role of Se:Hg molar ratios in different internal tissues particularly in fish of economic importance.

Acknowledgements. This study was partially supported by a DURSI grant (2009SGR-403) and by the fellowships A/015863/08 and A/023585/09 provided by AECID. Authors wish to thank personnel at the "Centres Científics i Tecnològics de la Universitat de Barcelona (CCiTUB)" for their assistance in the analytical process. Catarina Eira is supported by PI6421 in MARES (CENTRO-07-ST24FEDER-002033), QREN, Mais Centro - PORC and EU/ERDF.

\section{References}

Aksu A., Balkis N., Taşkin O.S., Erşan M.S. 2011. Toxic metal (Pb, $\mathrm{Cd}, \mathrm{As}$ and $\mathrm{Hg}$ ) and organochlorine residue levels in hake (Merluccius merluccius) from the Marmara Sea, Turkey. Environmental Monitoring and Assessment, 182, 509-521. DOI: $10.1007 / \mathrm{s} 10661-011-1893-1$.

Burger J., Gochfeld M. 2011. Mercury and selenium levels in 19 species of saltwater fish from New Jersey as a function of species, size, and season. Science of the Total Environment, 409, 1418-1429. DOI: 10.1016/j.scitotenv.2010.12.034.

Burger J., Gochfeld M. 2012. Selenium and mercury molar ratios in saltwater fish from New Jersey: individual and species variability complicate use in human health fish consumption advisories. Environmental Research, 114, 12-23. DOI: 10 1016/j.enres.2012.02.004.

Burger J., Gochfeld M. 2013. Selenium/mercury molar ratios in freshwater, marine, and commercial fish from the USA: variation, risk, and health management. Reviews on Environmental Health, 28, 129-143. DOI: 10.1515/reveh-2013-0010.

Carvalho C.M.L., Chew E.H., Hashemy L.I., Lu J., Holmgren A. 2008. Inhibition of the human tioredoxin system - A molecular mechanism of mercury toxicity. Journal of Biological Chemistry, 283, 11913-11923. DOI: 10.1074/jbc.M7101 33200.

Dang F., Wang W. 2011. Antagonistic interaction of mercury and selenium in a marine fish is dependent on their chemical species. Environmental Science \& Technology, 45, 3116-3122. DOI: 10.1021/es103705a.

Dural M., Genc E., Sangun M.K., Güner Ö. 2011. Accumulation of some heavy metals in Hysterothylacium aduncum (Nematoda) and its host sea bream, Sparus aurata (Sparidae) from NorthEastern Mediterranean Sea (Iskenderum Bay). Environmental Monitoring and Assessment, 174, 147-155. DOI: 10.1007/ s10661-010-1445-0.

Eira C., Torres J., Miquel J., Vaqueiro J., Soares A.M.V.M., Vingada J. 2009. Trace element concentrations in Proteocephalus macrocephalus (Cestoda) and Anguillicola crassus (Nematoda) in comparison to their fish host, Anguilla anguilla in Ria de Aveiro, Portugal. Science of the Total Environment, 407, 991-998. DOI: 10.1016/j.scitotenv.2009.10.040.

Kaneko J.J., Ralston N.V.C. 2007. Selenium and mercury in pelagic fish in the central north Pacific near Hawaii. Biological Trace Element Research, 119, 242-254. DOI: 10.1007/s12011-0078004-8.

Mezghani-Chaari S., Hamza A., Hamza-Chaffai A. 2011. Mercury contamination in human hair and some marine species from Sfax coasts of Tunisia: levels and risk assessment. Environmental Monitoring and Assessment, 180, 477-487. DOI: 10. 1007/s10661-010-1800-1.

Official Journal of the European Union, Commission Regulation (EC) n.1881/2006 JO L364, 20.12.2006. L364/5-L364/24

Peterson S.A., Ralston N.V.C., Whanger P.D., Oldfield J.E., Mosher W.D. 2009a. Selenium and mercury interactions with emphasis on fish tissue. Environmental Bioindicators, 4, 318-334. DOI: $10.1080 / 15555270903358428$.

Peterson S.A., Ralston N.V.C., Peck D.V., Van Sickle J., Robertson J.D., Spate V.L., Morris J.S. 2009b. How might selenium moderate the toxic effects of mercury in stream fish in western US? Environmental Science \& Technology, 43, 39193925. DOI: $10.1021 / \mathrm{es} 803203 \mathrm{~g}$.

Pinheiro M.C.N., do Nascimento J.L.M., Silveira L.C.L., da Rocha J.B.T., Aschner M. 2009. Mercury and selenium - A review on aspects related to the health of human populations in the Amazon. Environmental Bioindicators, 4, 222-245. DOI: 10. $1080 / 15555270903143440$ 
Ralston N.V.C. 2008. Selenium health benefit values as seafood safety criteria. Eco-Heath, 5, 442-455. DOI: 10.1007/s10393008-0202-0.

Ralston N.V.C. 2009. Introduction to 2 nd issue on special topic: selenium and mercury as interactive environmental indicators. Environmental Bioindicators, 4, 286-290. DOI: 10.1080/ 15555270903448682.

Ralston N.V.C., Ralston C.R., Blackwell III J.L., Raymond L.J. 2008. Dietary and tissue selenium in relation to methylmercury toxicity. NeuroToxicology, 29, 802-811. DOI: 10.1016/j.neuro. 2008.07.007.

Rice G., Swartout J., Mahaffey K., Schoeny R. 2000. Derivation of US EPA's oral Reference Dose (RfD) for methylmercury. Drug and Chemical Toxicology, 23, 41-54. DOI: 10.1081/ DCT-100100101.

Scudder B.C., Chaser L.C., Wentz D.A., Bauch N.J., Brigham M.E., Moran P.W., Krabbenhoft D.P. 2009. Mercury in fish bed sediment and water from streams across the United States, 19982005. US Department of Interior, Report 2009-5109. Reston, Virginia, USA, 74 pp.

Serbaji M.M., Azri C., Medhioub K. 2012. Anthropogenic contributions to heavy metal distributions in the surface and sub-surface sediments of the northern coast of Sfax, Tunisia. International Journal of Environmental Research, 6, 613-626.

Sørmo E.G., Ciesielski T.M., Overjordet I.B., Lierhagen S., Eggen G.S., Berg T., Jenssen B.M. 2011. Selenium moderates mercury toxicity in free-ranging freshwater fish. Environmental Science \& Technology, 45, 6561-6566. DOI: 10.1021/es $200478 b$.

Sures B. 2002. Competition for minerals between Acanthocephalus lucii and its definitive host pearch (Perca fluviatilis). International Journal for Parasitology, 32, 1117-1122. DOI: 10.1016/S0020-7519(02)00083-8.

Received: March 20, 2014

Revised: April 11, 2014

Accepted for publication: June 27, 2014
Sures B. 2003. Accumulation of heavy metals by intestinal helminths in fish: an overview and perspective. Parasitology, 126, S53S60. DOI: 10.1017/S003118200300372X.

Sures B. 2008. Environmental Parasitology. Interactions between parasites and pollutants in the aquatic environment. Parasite, 15, 434-438.

Sures B., Siddall R., Taraschewski H. 1999. Parasites as accumulation indicators of heavy metal pollution. Parasitology Today, 15, 16-22. DOI: 10.1016/S0169-4758(98)01358-1.

Türkmen M., Türkmen A., Tepe Y., Ates A., Gökkus K. 2008. Determination of metal contaminations in sea foods from Marmara, Aegean and Mediterranean seas: twelve fish species. Food Chemistry, 108, 794-800. DOI: 10.1016/j.foodchem.2007. 11.025 .

USA/EPA 1998. Report on the Peer Consultation Workshop on Selenium Aquatic Toxicity and Bioaccumulation. Office of Water, U.S. Environmental Protection Agency, Washington D.C., USA.

Usero J., Izquierdo C., Morillo J., Gracia I. 2003. Heavy metals in fish (Solea vulgaris, Anguilla anguilla and Liza aurata) from salt marshes on the southern Atlantic coast of Spain. Environment International, 29, 949-956. DOI: 10.1016/S01604120(03)00061-8.

WHO 1987. Selenium. In: Environmental Health Criteria No 58. World Health Organization, Geneva, Switzerland, 306 pp.

WHO 2007. Public Health and Environment World Health Organization. WHO Document Production Services, Geneva, Switzerland. 